\title{
CORRECTION
}

\section{Correction: E. coli Nissle 1917 is a safe mucosal delivery vector for a birch-grass pollen chimera to prevent allergic poly-sensitization}

\author{
P. J. Sarate ${ }^{1}$, S. Heinl ${ }^{2}$, S. Poiret ${ }^{3}$, M. Drinić ${ }^{1}$, C. Zwicker ${ }^{1}$, I. Schabussova ${ }^{1}$, C. Daniel ${ }^{3}$ and U. Wiedermann ${ }^{1}$
}

Mucosal Immunology (2019) 12:291; https://doi.org/10.1038/s41385-018-0103-7

Correction to: Mucosal Immunology; https://doi.org/10.1038/ s41385-018-0084-6

Following the publication of this article, the authors have requested that the Acknowledgements section be amended to include the financing source of the study. The correct Acknowledgments should be as follows:
We gratefully acknowledge funding from the Austrian Science Fund SFB F46 and DK MCCA W1248-B30, OeAD-GmbH grants (FR13/2016) and from the Amadeus partnership Hubert Curein French and Austrian program. We thank the Biolmaging Center of Lille (Frank Lafont) for the use of the IVIS Lumina XR. We gratefully thank Katharina Ambroz, Elke Korb, Karin Baier, Erika Garner-Spitzer, Joshua Tobias, Gwenaëlle Verbrugghe, and Jéremy Desramaut for their technical assistance and helpful discussions.

\footnotetext{
${ }^{1}$ Institute of Specific Prophylaxis and Tropical Medicine, Medical University of Vienna, Vienna, Austria; ${ }^{2}$ Department of Biotechnology, University of Natural Resources and Life

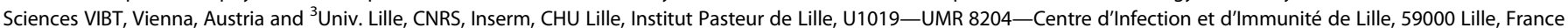
Correspondence: C Daniel (catherine.daniel@ibl.cnrs.fr) or U Wiedermann (ursula.wiedermann@meduniwien.ac.at)

These authors contributed equally: C. Daniel, U. Wiedermann.
}

Published online: 1 November 2018 